\title{
Brigitte Louichon, Romancières sentimentales (1789-1825)
}

\section{Michel Arrous}

\section{(2) OpenEdition \\ 1 Journals}

\section{Édition électronique}

URL : http://journals.openedition.org/studifrancesi/3759

DOI : 10.4000/studifrancesi.3759

ISSN : 2421-5856

Éditeur

Rosenberg \& Sellier

\section{Édition imprimée}

Date de publication : 1 décembre 2012

Pagination : $578-579$

ISSN : 0039-2944

\section{Référence électronique}

Michel Arrous, « Brigitte Louichon, Romancières sentimentales (1789-1825) », Studi Francesi [En ligne],

168 (LVI | III) | 2012, mis en ligne le 30 novembre 2015, consulté le 06 mars 2021. URL : http:// journals.openedition.org/studifrancesi/3759; DOI : https://doi.org/10.4000/studifrancesi.3759

Ce document a été généré automatiquement le 6 mars 2021.

\section{(c) (i) (9)}

Studi Francesi è distribuita con Licenza Creative Commons Attribuzione - Non commerciale - Non opere derivate 4.0 Internazionale. 


\title{
Brigitte Louichon, Romancières sentimentales (1789-1825)
}

\author{
Michel Arrous
}

\section{RÉFÉRENCE}

BRIGITTE LOUICHON, Romancières sentimentales (1789-1825), Saint-Denis, Presses

Universitaires de Vincennes, 2009, pp. 343.

1 Dans la continuité des travaux de Margaret Cohen et d'Ellen Constans, l'entreprise de Brigitte Louichon vise moins à réhabiliter une littérature injustement oubliée - les éditions de certaines de ces auteures se sont multipliées depuis l'époque où Jean Gaulmier préfaçait Claire d'Albe - qu'à lui donner sa place dans l'histoire littéraire. Autres signes de ce renouveau, le collectif dirigé par A. Del Lungo et B. Louichon, La Littérature en bas-bleus. Romancières sous la Restauration et la monarchie de Juillet (Garnier, 2010), et les textes réunis et présentés par C. Mariette-Clot et D. Zanone, La Tradition des romans de femmes XVIII ${ }^{e}$ XIX $X^{e}$ siècles (Champion, 2012). Le roman sentimental, c'est bien sûr Mmes Cottin, la romancière la plus emblématique de l'époque, de Duras, de Genlis, de Krüdener, de Souza, mais aussi Sophie Gay dont la plus belle œuvre fut sa fille, et, inattendue en cette compagnie, Mme de Staël dont la présence dans la catégorie des «femmes auteurs» avait déjà été discutée par Mme de Genlis qui la voyait en «femme philosophe».

2 L'intérêt de l'ouvrage réside pour une part dans un parti-pris de lecture risqué sinon impossible, puisqu'il s'agit de lire ces romans «en faisant comme si Balzac et Stendhal n'avaient rien publié, en faisant comme si on ne savait pas tout ce que le roman serait au siècle naissant». Plus réussi et surtout plein d'enseignement nous paraît le dialogue établi entre ces œuvres dont on a souvent relevé l'uniformité parce qu'on n'a pas su les mettre en perspective afin de discerner leurs nuances et leurs différences. La plupart de ces romancières à succès, qui ont enchanté la jeunesse d'Emma Bovary, sont des disciples de Rousseau dont elles reprennent le système romanesque tout en en 
proposant une lecture désenchantée, comme on le voit dans Delphine, dans Adèle de Sénange de Mme de Souza (1794), dans Claire d'Albe de Mme Cottin (1799) ou dans Valérie de Mme de Krüdener (1803). Mais se fait aussi sentir l'influence de Werther, de Pamela et des Lettres de milady Catesby de Mme Riccoboni. À l'exception d'Ourika, les premières œuvres de ces romancières sont des romans épistolaires, forme connue et éprouvée comme un excellent outil d'analyse de la passion, en partie abandonnée au profit de la narration à la troisième personne. Ainsi sera contournée la difficulté majeure du roman par lettres «où chaque style doit être aussi distinct que le caractère de ceux qui écrivent» (Mme Cottin, préface de Malvina, 1801). D’où la progressive désaffection du roman par lettres et sa condamnation au nom de la vraisemblance et du «naturel», si bien que certaines romancières, telle Mme de Genlis, imposent au lecteur un discours sur la fiction qui finit parfois par éclipser le personnage.

3 La relation amoureuse est au centre de ces romans: c'est le cas de Mmes Cottin, de Staël, de Krüdener qui racontent l'amour-passion, alors que Mme de Genlis le stigmatise ou que Mme de Souza privilégie la famille. Ce désintérêt ne manque pas d'être sanctionné par les lecteurs qui réclament des romans où le romanesque l'emporte. Les chapitres 6 et 7 abordent la saisie temporelle dans ces romans où, curieusement, en dépit de l'expérience révolutionnaire, la référence au passé est souvent absente. Alors qu'ils ont enflammé toute une génération, pourquoi ont-ils été si vite oubliés? Sans doute parce qu'ils ne s'inscrivaient pas suffisamment dans la réalité contemporaine, mais aussi parce qu'ils utilisaient les mêmes moyens et les mêmes modèles, entre autres un schéma si souvent reproduit qu'il vira au poncif: l'aveu, le serment, le vœu, et leur contrepartie - le silence et le secret. Sans doute aussi aurait-il fallu pousser plus loin l'analyse stylistique pour préciser en quoi l'écriture de ces préromantiques était novatrice, car il ne semble pas que leur volonté de revivifier le langage de la sensibilité ait suffi à assurer leur pérennité. Contrepoint à cette étude, le dernier chapitre: «Lecture d'Armance». Si on réinscrit le premier roman de Stendhal dans le contexte de l'époque, on peut y voir une transposition plutôt ironique des romans de femmes que Stendhal connaissait fort bien. Le caractère incompréhensible qu'il a eu pour ses premiers lecteurs ne tient pas au secret non avoué - la stratégie du secret était banale - mais aux pratiques d'un narrateur omniscient et retors qui compromet la vraisemblance puisqu'il ne cesse de faire entendre les pensées les plus intimes du héros sans jamais révéler son secret. D’où la déception de lecteurs habitués aux modalités du roman sentimental dont le programme narratif est fortement balisé. Dans le cas d'Armance, ils ne pouvaient tirer parti d'un savoir réputé supérieur à celui des personnages. Le narrateur stendhalien ne joue pas le jeu du narrateur du roman sentimental, il n'en respecte pas les conventions, allant même par endroits jusqu'à parodier le genre.

4 Ces Romancières sentimentales sont bien plus qu'un nécessaire complément à l'anthologie de Raymond Trousson (Romans de femmes $d u$ XVIII siècle, 1996). Elles retracent une brève étape dans une histoire qui va en France de La Nouvelle Héloïse à Dominique. On remerciera leur auteur d'avoir mis en évidence la richesse de ces textes oubliés dont certains, il faut le dire, n'ont rien perdu de leur lisibilité. 